\title{
Clinical Efficacy and Safety of Major Uterine Wall Resection and Reconstruction of the Uterus Combined with LNG-IUS for the Treatment of Severe Adenomyosis
}

\section{Klinische Wirksamkeit und Sicherheit von Uteruswandresektion und Uterusrekonstruktion in Verbindung mit LNG-IUS zur Behandlung schwerer Adenomyose}

\section{(우(1) (옹}

Authors

Cui Sun, Xiao-yan Ren, Yi Gao, Zhi-Gang Liang, Meng Mou, Heng-fang Gu, Yan-Bing Xiao

\section{Affiliation}

Gynecology Department of Affiliate Hospital of Maternal and Child Health Care of Zunyi Medical University, Zunyi, China

Key words

major uterine wall resection and reconstruction of the uterus, levonorgestrel-releasing intrauterine system, adenomyosis, clinical efficacy, safety

\section{Schlüsselwörter}

Uteruswandresektion mit Uterusrekonstruktion, Levonorgestrel-Intrauterinsystem, Adenomyose, klinische Wirksamkeit, Sicherheit

$$
\begin{array}{ll}
\text { received } & 17.12 .2018 \\
\text { revised } & 1.8 .2019 \\
\text { accepted } & 11.8 .2019
\end{array}
$$

\section{Bibliography}

DOI https://doi.org/10.1055/a-0995-2200

Published online 9.12. 2019 | Geburtsh Frauenheilk 2020; 80: 300-306 @ Georg Thieme Verlag KG Stuttgart · New York | ISSN 0016-5751

\section{Correspondence}

Yan-Bing Xiao

Gynecology Department of Affiliate Hospital of Maternal and Child Health Care of Zunyi Medical University Zhonghua street, Zunyi, Guizhou province 563000, PR China yanbing_xiao@163.com

\section{ABSTRACT}

Objective Aim of the study was to evaluate the clinical efficacy and safety of major uterine wall resection and reconstruction of the uterus (MURU) combined with a levonorgestrel-releasing intrauterine system (LNG-IUS) for the treatment of adenomyosis.
Methods Ninety patients diagnosed with adenomyosis were enrolled in this study. All participants were examined by transvaginal ultrasound (TVU) or magnetic resonance imaging (MRI). Serum levels of cancer antigen 125 (CA 125) were quantitatively measured. All patients underwent MURU in combination with LNG-IUS. The therapeutic safety of MURU was assessed during surgery and the patients' stay in hospital. The clinical efficacy was evaluated by comparatively analyzing changes in dysmenorrhea, volume of menstrual blood, uterine volume and serum levels of CA 125 before, and at 3, 6 and 12 months following MURU.

Results All 90 patients enrolled in the study were successfully treated with MURU combined with LNG-IUS. No significant complications were observed during surgery and hospital stay. The mean operation time, intraoperative blood loss and length of hospital stay were $82.4 \pm 13.8 \mathrm{~min}, 53.3 \pm 20.3 \mathrm{ml}$, and $4.3 \pm 0.8$ days, respectively. Dysmenorrhea completely disappeared in all patients. Uterine volume and serum levels of CA 125 were restored to normal ranges. No recurrence of adenomyosis was observed during postoperative follow-up.

Conclusion MURU combined with LNG-IUS is an efficacious and safe treatment for severe adenomyosis. This combined technique is not only effective to manage severe adenomyosis but also preserves as much of the uterus as possible.

\section{ZUSAMMENFASSUNG}

Zielsetzung Ziel dieser Studie war es, die klinische Wirksamkeit und Sicherheit der Uteruswandresektion gefolgt von Uterusrekonstruktion (MURU) in Verbindung mit LevonorgestrelIntrauterinsystemen (LNG-IUS) bei der Behandlung von Adenomyose zu evaluieren.

Methoden Neunzig mit Adenomyose diagnostizierte Patientinnen wurden in diese Studie aufgenommen. Alle Teilnehmerinnen wurden mit transvaginalem Ultraschall (TVUS) bzw. Magnetresonanztomografie (MRT) untersucht. Die Serumkonzentrationen des Tumormarkers CA-125 wurden gemessen. Alle Patientinnen unterzogen sich einer MURU-Operation 
in Kombination mit LNG-IUS. Die therapeutische Sicherheit des MURU-Eingriffs wurde während der Operation und dem darauffolgenden Krankenhausaufenthalt bewertet. Die klinische Wirksamkeit wurde evaluiert. Veränderungen bei den Symptomen der Dysmenorrhö, dem Ausmaß an Menstruationsblutung, im Uterusvolumen sowie Serumkonzentrationen von CA-125 vor sowie 3, 6 und 12 Monate nach dem MURU-Eingriff wurden gemessen.

Ergebnisse Alle 90 in der Studie aufgenommenen Patientinnen wurden erfolgreich mit MURU in Kombination mit LNGIUS behandelt. Es traten keine signifikanten Komplikationen während der Operation und dem Krankenhausaufenthalt auf. Die mittlere Operationsdauer, der mittlere intraoperative
Blutverlust und die mittlere Dauer des Krankenhausaufenthalts betrugen jeweils $82,4 \pm 13,8$ Minuten, 53,3 $\pm 20,3 \mathrm{ml}$ bzw. 4,3 $\pm 0,8$ Tage. Die Symptome von Dysmenorrhö verschwanden gänzlich bei allen Patientinnen. Gebärmuttervolumen und der CA-125-Spiegel normalisierten sich. Bei keiner Patientin trat Adenomyose in der Nachbeobachtungszeit wieder auf.

Schlussfolgerung MURU in Verbindung mit LNG-IUS ist eine effektive und sichere Methode zur Behandlung schwerer Adenomyose. Diese kombinierte Technik stellt eine effektive Methode zur Behandlung schwerer Adenomyose dar und erhält zudem noch einen Teil der Gebärmutter.

\section{Introduction}

Adenomyosis is a common gynecological disease; it occurs in more than $10 \%$ of the female population and the incidence is increasing. Typical symptoms include dysmenorrhea and menstrual anomalies which significantly interfere with the reproductive health and quality of life of affected women. Currently, multiple approaches are used to treat adenomyosis in clinical practice. However, all of these therapeutic options have disadvantages or limitations, such as insufficient efficacy, adverse events or high risk of recurrence. Among the different options, it has been widely recognized that hysterectomy remains the primary treatment for adenomyosis, especially for advanced-stage adenomyosis [1-3].

The non-contraceptive benefits of levonorgestrel-releasing intrauterine system (LNG-IUS), particularly its impact on dysmenorrhea and heavy menstrual bleeding, have been proven to be effective for the management of adenomyosis in many clinical trials [4-6]. LNG-IUS can significantly and effectively alleviate the severity of dysmenorrhea in the majority of affected women. In a randomized comparative study [7], quality of life was found to be considerably improved in women undergoing hysterectomy in combination with LNG-IUS at the postoperative follow-up 1 year after surgery. Saremi et al. [8] successfully used a novel conservative surgical procedure consisting of adenomyomectomy to treat adenomyosis and achieved relatively safe surgical outcomes, which is especially appropriate when treating women who seek to preserve their uterus and fertility.

Our research team has focused on exploring efficacious and safe treatment options for adenomyosis. Based on our previous work, we advocate an approach based on modifying and improving the clinical therapy of adenomyosis. The standard parameters used to evaluate the improved treatment include maximum thickness of the uterine muscle wall in patients with diffuse adenomyosis or maximum adenomyoma diameter in women with adenomyosis. The therapeutic options are evaluated based on these standard parameters. Based on this novel concept, our research team has proposed three individualized IUS programs for different patients, according to the severity of lesions. The design of the three IUS programs combines IUS with high-intensity focused ultrasound (HIFU), GnRH or major uterine wall resection and reconstruction of the uterus (MURU).
In one of the three IUS programs, LNG-IUS was combined with major uterine wall resection and reconstruction of the uterus (MURU) to treat women diagnosed with severe adenomyosis/adenomyoma, who had not undergone treatment with alternative therapeutic options. The current study was designed to assess the clinical efficacy and safety of this combined technique for the treatment of women diagnosed with adenomyosis, especially those with severe symptoms, and to provide evidence for the clinical application of this novel therapy.

\section{Materials and Methods}

\section{Baseline data}

Ninety patients diagnosed with adenomyosis in the Department of Gynecology, Affiliate Hospital of Maternal and Child Health Care of Zunyi Medical University between June 2012 and August 2014, based on a history of dysmenorrhea, bimanual examination, transvaginal ultrasound (TVU)/magnetic resonance imaging (MRI) and $\mathrm{CA}_{125}$ levels, were recruited into this study. Patients were divided into three groups according to severity of disease, based on the maximum diameter (MD) of the adenomyoma or extent of adenomyosis (in the anterior, posterior uterine wall or fundus of the uterus) measured by TVU or MRI. Based on their MD measurements, women were classified as having mild (MD $<35 \mathrm{~mm}$ ), moderate (MD 35-50 mm) or severe disease (MD $>50 \mathrm{~mm}$ ). The study procedures were approved by the ethics committee of Zunyi Medical University. Written informed consent was obtained from all participants.

\section{Inclusion and exclusion criteria}

Patients with severe (MD > $50 \mathrm{~mm}$ ) and moderate disease (MD $35-50 \mathrm{~mm}$ ) who had not been treated with HIFU or had refused HIFU were included in this study. Patients with mild disease (MD $<35 \mathrm{~mm}$ ) who wished to retain their fertility and patients for whom surgery was contraindicated were excluded from the study.

\section{MURU combined with LNG-IUS}

Conventional laparotomy was performed under general anesthesia, starting with a 5-7 cm transverse incision of the lower abdomen. A towel clamp was used to hold the uterine body and pull it 
out of the abdominal wall. Adhesions were separated when necessary. The uterine vessels were ligated close to the isthmus using a tourniquet. The myometrium was longitudinally incised along the midline of the uterine fundus to the bottom of uterine cavity, approximately $0.5-1 \mathrm{~cm}$ under the uterine serosa. The myometrium was split and separated downward to the superior border of the uterine isthmus (exterior incision). Subsequently, the myometrium (interior incision) was separated downward to the isthmus approximately $0.5-1 \mathrm{~cm}$ from the endometrium. The exterior and interior incisions were converged in the uterine isthmus when the uterus became the pyriform shape. A large part of the myometrial tissue between the exterior and interior incisions and above the isthmus was resected. Redundant uterine tissue in the seromuscular and mucous layers was resected. The LNG-IUS tail filament was approximately $3-4 \mathrm{~cm}$ long, and a knot was tied at the end. The redundant wire of the IUS was removed. The IUS was inserted into the uterine cavity, the uterine mucosa was sutured with 2/0 absorbable sutures to reconstruct the uterine cavity, and bilateral seromuscle were pulled to the center line and sutured using 2/0 absorbable interrupted sutures to create a new uterus. The tourniquet was removed when bleeding had stopped. The abdominal cavity was washed and sutured layer by layer. A drainage tube was placed where necessary.

\section{Requirements for uterine reconstruction}

The uterine cavity had to be reconstructed in such a manner that it would be capable of holding an IUS or a slightly larger device. The aim was also to ensure that the thickness of the myometrial layer after uterine cavity reconstruction was less than $30 \mathrm{~mm}$ and that the uterine volume would be the same or even slightly smaller than that of similar women of childbearing age [9]. Uterine volume was calculated according to the formula: $V=\pi / 6 \times a \times b \times c$ ( $V$ refers to the uterine volume; $a, b$ and $c$ denote the uterine length, width and thickness measured by ultrasound, respectively) [10].

\section{Weight and volume of excised muscle tissue}

All excised muscle tissues were weighed. To measure the volume of resected tissue, all resected muscle tissues were placed in a beaker filled with water. The volume of the outflow was equal to the volume of the excised muscle tissue. The excised muscle tissues were then prepared for histopathological examination.

\section{Evaluation of clinical efficacy and safety}

The operation time, intraoperative blood loss, postoperative complications and the length of hospital stay were used to evaluate the safety of the procedure. At 3, 6 and 12 months postoperatively, patients were followed up and the following parameters were evaluated: symptoms of dysmenorrhea, menstrual blood volume, uterine volume (measured by TVU or MRI) and serum CA 125 levels. The extent of dysmenorrhea was evaluated using a visual analogue scale (VAS) [11]. Menstrual blood volume was estimated using the Sensation Quantity Scale (SQS), with values obtained from patients who self-estimated the changes in menstrual volume before and after surgery. Reported volumes ranged from extensive to zero (amenorrhea). The SQS was divided into six degrees as follows: very large amount, large amount, moderate
- Table 1 Baseline characteristics of the enrolled patients $(n=90)$.

\begin{tabular}{|l|c|}
\hline Variable & \\
\hline Moderate adenomyosis & $\mathrm{n}=37$ \\
\hline Severe adenomyosis & $\mathrm{n}=53$ \\
\hline Mean age & $39.67 \pm 10.31$ (years) \\
\hline Mean VAS & $6.3 \pm 3.3$ \\
\hline Mean SQS & $4.2 \pm 0.4$ \\
\hline
\end{tabular}

amount, small amount, very slight amount and zero, and were represented by a corresponding score of 5, 4, 3, 2, 1 and 0 points, respectively.

\section{Statistical analysis}

All data analyses were performed using the SPSS 17.0 statistical software package (SPSS Inc., Chicago, IL, USA). Data are expressed as mean \pm standard deviation (SD). The differences between two groups were compared using Student's t-test. A p value of less than 0.05 was considered statistically significant.

\section{Results}

\section{Baseline characteristics}

A total of 90 patients who met the inclusion criteria were enrolled in this study. Of these patients, 37 cases were classified as having a moderate adenomyosis and 53 women were classed as having severe adenomyosis. All patients manifested varying degrees of dysmenorrhea and increasing menstrual blood volumes preoperatively, especially patients with moderate and severe adenomyoma. The preoperative mean VAS and SQS scores were calculated as $6.3 \pm 3.3$ and $4.2 \pm 0.4$, as shown in $>$ Table 1 .

\section{Clinical efficacy of MURU combined with LNG-IUS}

Prior to surgery, the average uterine volume was $273.7 \pm$ $109.7 \mathrm{~cm}^{3}$ in all 90 patients. The average weight of removed uterine muscle tissue was $329.1 \pm 189.6 \mathrm{~g}$, approximately 5.49 times that of a normal uterine weight of $60 \mathrm{~g}(\mathrm{p}<0.05)$. At postoperative 3 months, the average uterine volume was $58.9 \pm 18.6 \mathrm{~cm}^{3}$. At postoperative follow-up, the uterine volume was slightly smaller than that of a normal uterus. The procedures used for MURU combined with LNG-IUS are shown in > Fig. 1.

\section{Safety of MURU Combined with LNG-IUS}

MURU combined with LNG-IUS was successfully performed in all 90 women. The average operation time was $82.4 \pm 13.8 \mathrm{~min}$ and the mean intraoperative blood loss was $53.3 \pm 20.3 \mathrm{ml}$. Postoperatively, slight incisional fat degeneration occurred in three patients, which recurred soon after anti-inflammatory therapy. The average length of hospital stay was $4.3 \pm 0.8$ days. No complications occurred during surgery or the postoperative period in any patients. The pathological examination of the excised uterine tissues confirmed the diagnosis of adenomyosis in all patients. 

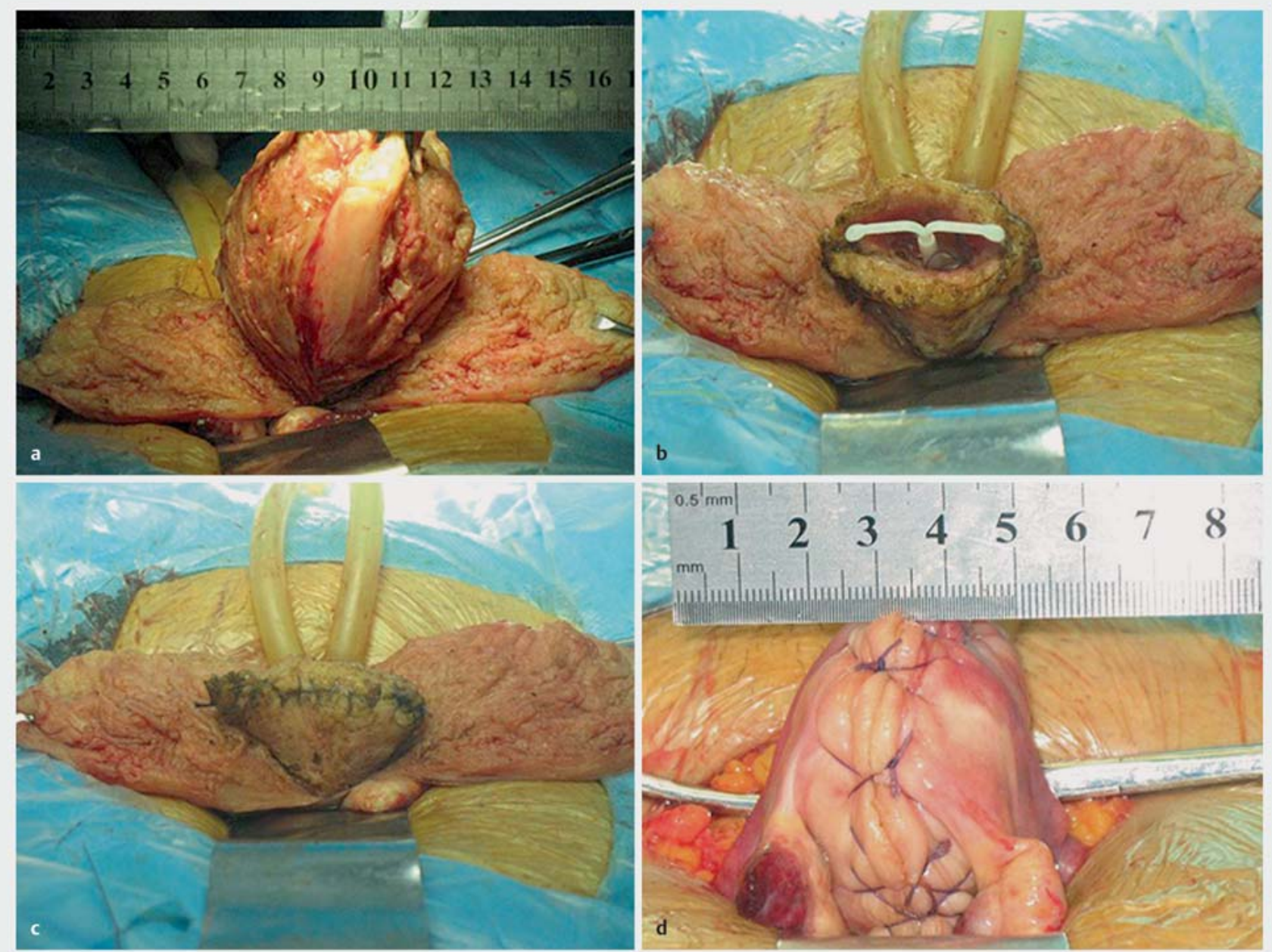

- Fig. 1 Surgical procedure of MURU + LNG-IUS. a The myometrium was incised and separated at $0.5-1 \mathrm{~cm}$ beneath the serosa downward to the superior border of isthmus bilaterally; b LNG-IUS is placed in the uterine cavity; $\mathbf{c}$ The uterine cavity is reconstructed; $\mathbf{d}$ The uterus is completely reconstructed.

\section{Postoperative Complications}

At 3 months after surgery, the incidence of amenorrhea, oligomenorrhea and slight menstruation was $38.9 \%(n=35), 53.33 \%$ $(n=48)$ and $7.78 \%(n=7)$, respectively. Symptoms of dysmenorrhea had disappeared completely. Serum CA 125 levels had decreased to normal ranges. TVU/MRI showed that the uterine size and morphology had been restored to normal ranges ( $\bullet$ Table 2, Figs. 2 and 3 ).

\section{Discussion}

Adenomyosis is most commonly diagnosed in middle-aged women. Complete removal of adenomyoma lesions during surgery can decrease the risk of recurrence and create a favorable uterine environment for pregnancy [8]. MURU combined with LNG-IUS can be used to entirely resect lesions in patients with adenomyosis. In this study, MURU was a novel approach to treat women with adenomyosis wishing to preserve their fertility. Consequently, the safety of the MURU procedure was the top priority. All patients were successfully treated by MURU combined with IUS. Three patients had mild incisional fat degeneration after surgery; no other complications occurred during or after surgery, suggesting that MURU combined with IUS implantation is a safe procedure to treat adenomyosis. During postoperative follow-up, symptoms of dysmenorrhea completely disappeared and serum CA 125 levels decreased to normal ranges in all patients. No postoperative recurrence was observed. These favorable outcomes validate the clinical efficacy of this combined technique.

Adenomyosis manifests as dysmenorrhea and increased menstrual volume. Repeated bleeding and fibrosis of the ectopic lesions contribute to dysmenorrhea. The main reason for the increase in menstrual volume is thickening of the endometrium and weakening of the myometrium. Dysmenorrhea and hemorrhage are generally positively correlated with lesion size and severity of disease, with adenomyosis symptoms often correlated with the course of disease. Patients with severe adenomyosis frequently manifest with significant dysmenorrhea and hemorrhage. 
After combined treatment consisting of MURU and LNG-IUS, the symptoms of dysmenorrhea disappeared completely and menstrual volume was significantly reduced in all patients. A large number of myometrium lesions was removed and the uterine cavity was significantly reduced after MURU. LNG-IUS has been proven to reduce menstrual volumes or even lead to amenorrhea and has therefore been used to treat mild adenomyosis $[12,13]$. The removal of lesions and placement of LNG-IUS can collectively mitigate the symptoms of hypermenorrhea and dysmenorrhea.

Therapeutic options for adenomyosis can be divided into conservative and surgical approaches. Conservative approaches such as medication and physiotherapy treat adenomyosis while preserving the uterus. The standard surgical option is hysterectomy. Both methods have their respective limitations, including low clinical efficacy, adverse events, high cost and high rate of recurrence. [14]. HIFU treatment can achieve therapeutic benefits in certain patients [15], but it does not adequately treat diffuse adenomyosis affecting the whole myometrium. In addition, HIFU equipment is very expensive. Conservative surgical options, such as uterine artery embolization (UAE), transcervical resection of the endometrium (TCRE) and lesion resection also have their limitations, especially when treating patients with severe adenomyosis [16-19].

Hysterectomy remains the main treatment for severe adenomyosis. Although adenomyosis can be treated by hysterectomy, this approach can still result in adverse events or even recurrence $[20,21]$. Most patients diagnosed with adenomyosis want to preserve their uterus $[9,22]$. Hysterectomy can lead to pelvic floor dysfunction, premature ovarian failure, affective disorder and family problems [23-25]. In addition to the traditional approach consisting of lesion resection, Nishida et al. have also described a novel type of surgery to treat diffuse adenomyosis [26]. However, their approach is limited to excising part of the muscle wall. With MURU, all of the myometrium between the serosa (interior 0.5$1 \mathrm{~cm}$ ) and endometrium (exterior $0.5-1 \mathrm{~cm}$ ) and above the uterine isthmus is resected. Moreover, the enlarged uterine cavity is reduced to a diameter of $3-4 \mathrm{~cm}$. MURU therefore differs significantly from the localized excision approach proposed by Nishida. Although MURU has been used to treat severe adenomyosis, the use of this procedure is still in its exploratory stages and will need to be further improved with experience and changes to surgical standards. When we used this novel approach in our study, we noted the following items which could improve outcomes after MURU. Firstly, the residual myometrial tissue on the serosa and
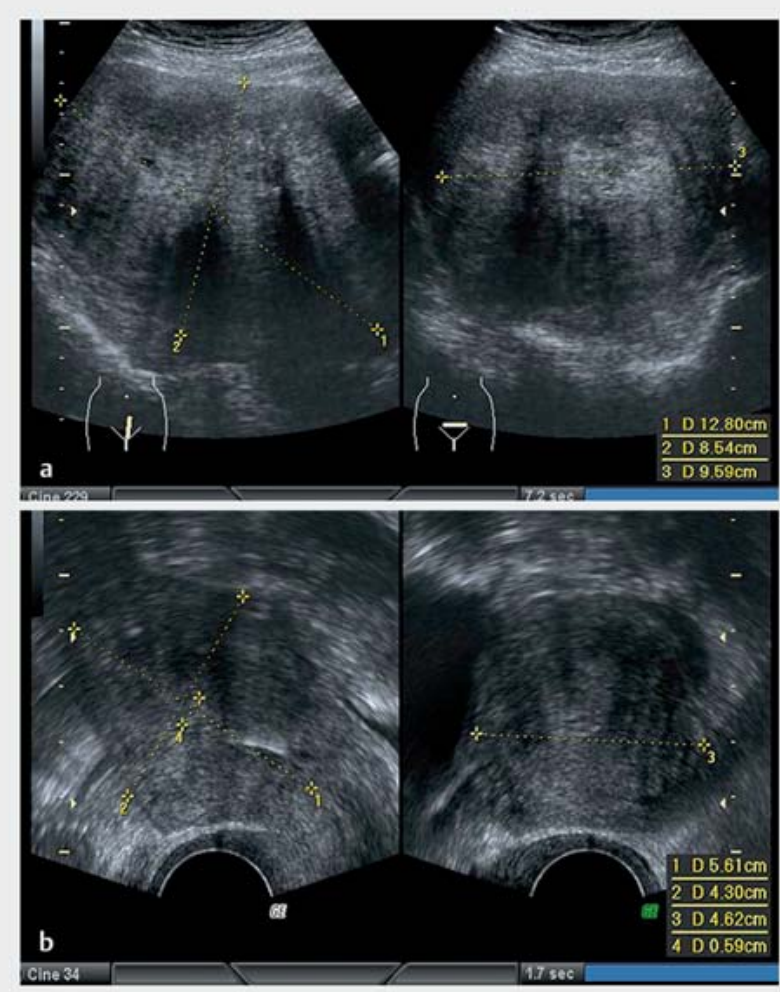

Fig. 2 Ultrasound of a case with severe uterine adenomyosis. a Preoperative ultrasound of severe uterine adenomyosis, uterine size: $12.80 \times 8.54 \times 9.59 \mathrm{~cm}^{3}$; b Ultrasound of severe uterine adenomyosis at 3 months postoperatively, uterine size: $5.61 \times 4.30 \times 6.42 \mathrm{~cm}^{3}$.

endometrium side should be less than $1 \mathrm{~cm}$ during surgery. Secondly, the volume of the uterine cavity should be reduced until it is able to contain one LNG-IUS or a slightly larger device. Thirdly, the excess muscle tissue should be removed before suturing the serosa and mucous layers to ensure that fewer lesions are left after uterine reconstruction. Fourthly, it is very important to pay attention to complete suture and prevent uterine bleeding. In addition, ligature of the uterine artery on both sides of the uterus should be avoided, especially adjacent to the lower uterine segment. Intraoperatively, electric knife should be maintained at an appropriate distance from the uterine, it might destroy the resid-

- Table 2 Comparison of different parameters before and after MURU combined with LNG-IUS $(n=90)$.

\begin{tabular}{|l|c|c|c|c|}
\hline & Preoperative & Postoperative & $\mathbf{1 2}$ months \\
\cline { 2 - 5 } & & $\mathbf{3}$ months & $\mathbf{6}$ months & $0.0^{*}$ \\
\hline VAS & $6.3 \pm 3.3$ & $0.0^{*}$ & $0.4 \pm 0.2^{*}$ & $0.7 \pm 0.4^{*}$ \\
\hline SQS & $4.2 \pm 0.4$ & $0.5 \pm 0.3^{*}$ & $52.9 \pm 11.9^{*}$ & $59.9 \pm 12.5^{*}$ \\
\hline CA $\left(\mathrm{cm}^{3}\right)$ & $273.7 \pm 109.7$ & $58.9 \pm 18.6^{*}$ & $14.7 \pm 6.7^{*}$ & $11.6 \pm 6.7^{*}$ \\
\hline${ }^{*} \mathrm{P}<0.05$ compared with preoperative values & $89.7 \pm 74.7$ & & \\
\hline
\end{tabular}



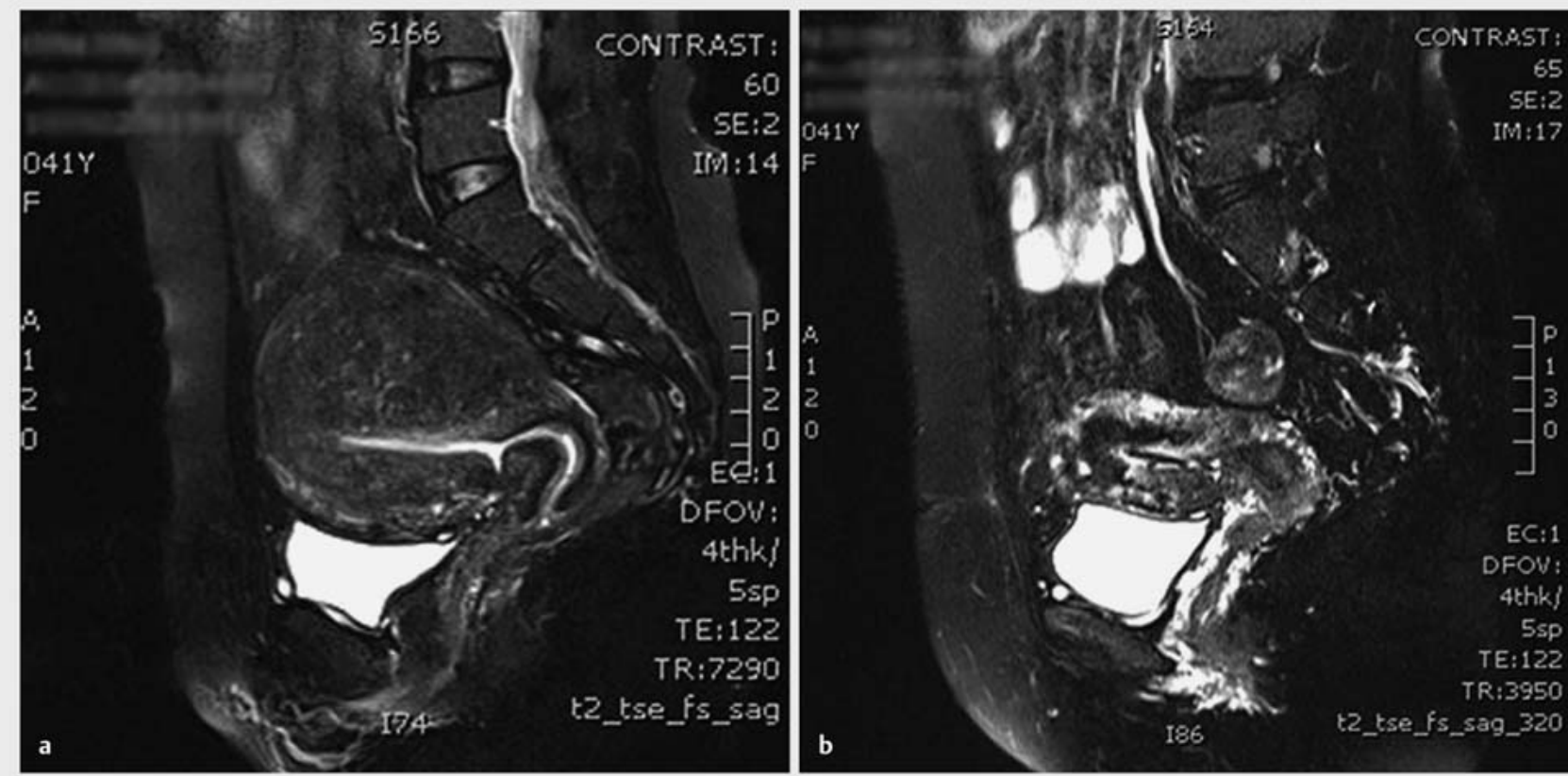

- Fig. 3 MRI of a case with severe uterine adenomyosis. a Preoperative MRI image of severe adenomyosis; b MRI image of severe adenomyosis at 3 months postoperatively.

ual lesions. Symmetry and aesthetics should be considered during uterine reconstruction. The postoperative size and appearance of the reconstructed uterus should resemble that of a normal uterus.

In recent years, LNG-IUS, a novel method for long-acting contraception, has begun to be used for non-contraceptive purposes. LNG-IUS can prevent the growth and recurrence of endometriosis lesions after the IUS is placed in the uterine cavity. LNG-IUS has also been found to be highly efficacious to treat mild adenomyosis [27]. A highly effective progestin, levonorgestrel can maintain high concentrations in the endometrium and has a long-lasting impact which can change aberrant endometrium to a more normal state [28]. Transforming the source of endometriosis is the basic approach favored by proponents of ectopic endometrium determinism [29]. IUS can partly prevent the recurrence of endometriosis.

The placement of an IUS into the uterus can significantly reduce lesion sizes in women with mild adenomyosis [30]. The underlying mechanism is still largely unknown, probably because levonorgestrel shrinks ectopic lesions in the myometrium, which are then absorbed by the body. However, these effects have not been observed in patients with severe adenomyosis, possibly because the effective component (levonorgestrel) of IUS is mainly released in the vicinity of the endometrium rather than the myometrium [31]. In this study, most lesions were excised by MURU, and the uterine wall became thinner after surgery $(\leq 30 \mathrm{~mm})$, which promoted the effect of IUS. Although a large number of lesions were excised, MURU still significantly differs from hysterectomy. Theoretically, it is impossible to completely remove all residual lesions with MURU. MURU should therefore be supple- mented by simple and efficient measures to prevent recurrence. LNG-IUS resolves this problem.

\section{Conclusion}

MURU can be used to excise adenomyosis lesions while preserving the uterus. LNG-IUS has a beneficial effect on mild adenomyosis and can help to prevent recurrence. Consequently, MURU combined with LNG-IUS is an efficacious and safe treatment for severe adenomyosis. Moreover, it is convenient and requires no special equipment, meaning that the combined procedure can be carried out in multi-level hospitals. Nevertheless, this novel technique is still in its early stages, and the long-term efficacy and safety remain to be elucidated. In addition, the impact on uterine hemodynamics and ovarian function is largely unknown and urgently requires further study.

\section{Acknowledgements}

This work was supported by tProject of National Natural Science Foundation of China (grant number 81460233, 81660293).

\section{Conflict of Interest}

The authors declare that they have no conflict of interest. 


\section{References}

[1] Yang JH, Ho HN, Yang YS. Current diagnostic and treatment strategies for adenomyosis. Expert Rev Obstet Gynecol 2006; 1: 111-120

[2] Popovic M, Puchner S, Berzaczy D et al. Uterine artery embolization for the treatment of adenomyosis: a review. J Vasc Interv Radiol 2011; 22: 901-909

[3] Wood C, Maher P, Hill D. Biopsy diagnosis and conservative surgical treatment of adenomyosis. J Am Assoc Gynecol Laparosc 1994; 1: 313316

[4] Bragheto AM, Caserta N, Bahamondes L et al. Effectiveness of the levonorgestrel-releasing intrauterine system in the treatment of adenomyosis diagnosed and monitored by magnetic resonance imaging. Contraception 2007; 76: 195-199

[5] Cho S, Nam A, Kim H et al. Clinical effects of the levonorgestrel-releasing intrauterine device in patients with adenomyosis. Am J Obstet Gynecol 2008; 198: 373.e1-373.e7

[6] Sheng J, Zhang WY, Zhang JP et al. The LNG-IUS study on adenomyosis: a 3-year follow-up study on the efficacy and side effects of the use of levonorgestrel intrauterine system for the treatment of dysmenorrhea associated with adenomyosis. Contraception 2009; 79: 189-193

[7] Ozdegirmenci O, Kayikcioglu F, Akgul MA et al. Comparison of levonorgestrel intrauterine system versus hysterectomy on efficacy and quality of life in patients with adenomyosis. Fertil Steril 2011; 95: 497-502

[8] Saremi A, Bahrami H, Salehian P et al. Treatment of adenomyomectomy in women with severe uterine adenomyosis using a novel technique. Reprod Biomed Online 2014; 28: 753-760

[9] JingHe L. Basis Endometriosis and clinical Research [M]. 1st ed. Beijing: China Union Medical University Press; 2003

[10] ter Haar G, Rivens I, Chen L et al. High Intensity Focused Ultrasound for the treatment of rat tumors. Phys Med Biol 1991; 36: 1405-1501

[11] Miller MD, Ferris DG. Measurement of subjective phenomena in primary care research: the visual analogue scale. Fam Pract Res J 1993; 13: 15-24

[12] Marjoribanks J, Lethaby A, Farquhar C. Surgery versus medical therapy for heavy menstrual bleeding. Cochrane Database Syst Rev 2006; (2): CD003855

[13] Bednarek PH, Jensen JT. Safety, efficacy and patient acceptability of the contraceptive and non-contraceptive uses of the LNG-IUS. Int I Womens Health 2010; 9: 45-58

[14] Maheshwari A, Gurunath S, Fatima F et al. Adenomyosis and subfertility: a systematic review of prevalence, diagnosis, treatment and fertility outcomes. Hum Reprod Update 2012; 18: 374-392

[15] Fukunishi H, Funaki K, Sawada K et al. Early results of magnetic resonance-guided focused ultrasound surgery of adenomyosis: analysis of 20 cases. J Minim Invasive Gynecol 2008; 15: 571-579
[16] Zhou M, Chen JY, Tang LD et al. Ultrasound-guided high-intensity focused ultrasound ablation for adenomyosis: the clinical experience of a single center. Fertil Steril 2011; 95: 900-905

[17] Siskin GP, Tublin ME, Stainken BF et al. Uterine artery embolization for the treatment of adenomyosis: clinical response and evaluation with MR imaging. AJR Am J Roentgenol 2001; 177: 297-302

[18] Pagedas AC, Boe IH, Perkins HE. Review of 24 cases of uterine ablation failure. J Am Assoc Gynecol Laparosc 1995; 2: 239

[19] Bohlman ME, Ensor RE, Sanders RC. Sonographic findings in adenomyosis of the uterus. AJR Am J Roentgenol 1987; 148: 765-766

[20] McCausland AM, McCausland VM. Depth of endometrial penetration in adenomyosis helps determine outcome of rollerball ablation. Am J Obstet Gynecol 1996; 174: 1786-93; 1793-1794

[21] Loffer FD. Endometrial ablation and resection. Curr Opin Obstet Gynecol 1995; 7: 290-294

[22] Speroff L, Glass RH, Kase NG. The Uterus. Clinical Gynecologic Endocrinology and Infertility. 6th ed. Baltimore, Md: Lippincott Williams \& Wilkins; 1999: Chapter 4, 340-347

[23] Laughlin GA, Barrett-Connor E, Kritz-Silverstein D et al. Hysterectomy, oophorectomy, and endogenous sex hormone levels in older women: the Rancho Bernardo Study. J Clin Endocrinol Metab 2000; 85: 645-651

[24] Rivera CM, Grossardt BR, Rhodes D] et al. Increased Mortality for Neurological and Mental Diseases following Early Bilateral Oophorectomy. Neuroepidemiology 2009; 33: 32-40

[25] Farquhar CM, Sadler L, Harvey SA et al. The association of hysterectomy and menopause: a prospective cohort study. BJOG 2005; 112: 956-962

[26] Nishida M, Takano K, Arai Y et al. Conservative surgical management for diffuse uterine adenomyosis. Fertil Steril 2010; 94: 715-719

[27] Bednarek PH, Jensen JT. Safety, efficacy and patient acceptability of the contraceptive and non-contraceptive uses of the LNG-IUS. Int J Womens Health 2010; 9: 45-58

[28] JingHe L. Several problems of basic and clinical research of endometriosis. Chinese Journal of Gynecology and Obstetrics 2002; 18: 129-130

[29] Wan YL, Holland C. The efficacy of levonorgestrel intrauterine systems for endometrial protection: a systematic review. Climacteric 2011; 14 : 622-632

[30] Cho S, Nam A, Kim H et al. Clinical effects of the levonorgestrel-releasing intrauterine device in patients with adenomyosis. Am J Obstet Gynecol 2008; 198: 373.e1-373.e7

[31] Sheng J, Zhang WY, Zhang JP et al. The LNG-IUS study on adenomyosis: a 3-year follow-up study on the efficacy and side effects of the use of levonorgestrel intrauterine system for the treatment of dysmenorrhea associated with adenomyosis. Contraception 2009; 79: 189-193 